\title{
Psychological profiling of participants at the Miss World contest via combined methodology: psychometric assessments and projective drawing
}

DOI: http://doi.org/10.26758/8.1.10

Kristina Brajovic Car (1), Aleksandra Đurić (2), Oana Pănescu (3)

(1) Faculty for Media and Communication, Department for Psychology, Belgrade, Serbia; email: kristina.brajovic.car@fmk.edu.rs

(2) Belgrade business school - Higher education institution for applied studies, Department for Social studies, Belgrade, Serbia; email: aleksandra.djuric@bbs.edu.rs

(3) Spiru Haret University, Faculty of Psychology and Educational Sciences, Bucharest, Romania; email: oanamadeleine@yahoo.com

Address correspondence to: Kristina Brajovic Car; E-mail: kristina.brajovic.car@fmk.edu.rs

\begin{abstract}
Objectives. We are discussing psychological consequences of consequences of embracing dominant cultural values.

Among them, beauty and its constant visual (and superficial) presentation become imperative criteria for self-evaluation during the growing up process for young girls. Visual criteria are more strongly connected to the perception of self-image compared to the self-evaluation criteria that was relevant for adolescents in the recent past.

Material and methods. On the sample of 20 young women, in the process of competition for Miss World their individual aspirations and profiles were analyzed and compared with the cultural trend. Profiling was done via Machover test and diagnostic interview in line with the drawing output as well as the psychometric evaluation based on the Driver test (35Q) dominant defense mechanisms of personality. Comparative analysis of cultural trends and individual profiles was conducted through interpretative analysis of results collected during psychological profiling of contestants through the theoretical model of Transactional analysis. Transactional analysis of the famous fairy tale Cinderella was reinterpreted in the classical Berne approach in order to make it more relevant for the current problems and issues of young girls.

Results. The central theme is the self-image that is not matching calendar age. Graphical and phenomenological self-reports show that many participants perceived themselves as a child. Selfvalidation and social context interpretation come from the regressive frame of reference.

Conclusions. The results strongly support the hypothesis that beauty contestants need to be carefully selected, motivated and supported in this personality challenging qualification and evaluation process based on one dimension.
\end{abstract}

Keywords: self-image, injunctions, drivers, beauty pageant, adolescent

\section{Introduction}

Contemporary use of the term star does not have a long history. The emergence of a modern concept and the phenomenon of stars were influenced by the occurrence of mass media, as well as the development of consumer culture in the Western capitalist societies of the twentieth 
century. The term "star" refers to a person who has a set of characteristics that distinguish him/her from the general population. In describing the stars, adjectives such as fame, glamor, spectacular, respectable, famous, popular and similar are most often used.

A complex categorization of celebrities was given by sociologist Chris Rojek (2001). He refers to three types of celebrities categorized according to the status of accomplished fame: status is assigned by a blood link (royal family, powerful families of politicians or business people); status is acquired by work or talent (athletes, artists, successful business people, all those with a rare talent or skill); status is attributed thanks to the media and the public's attention, whereby a person may and may not have a specific talent and quality (Graeme, 2004). This category also includes participants of beauty pageants, as well as the Miss World contestants.

Celebrities who have gained fame through the attention of the media and the public, including the participants of the beauty pageants (even for a short time) have mythological figures of contemporary culture. According to German sociologist Leo Lowenthal, this transition from the "idol of production" to the "idols of consumption" marked a change in the moral and value system those are the contents that the audience can easily adopt by reading magazines and watching entertainment shows (Schmid, 2014). This kind of shows enables escapism to the audience, encourages and offers an illusion of participation in this glamorous world that brings satisfaction. On the other hand, the difficulties through which people pass, for example, at the Miss World contest, provide consolation and facilitate the identification process for the audience. At one level, participants in beauty pageants are unrealistic ideals, and at the second level - faults and weaknesses can be found in them. In this way, the media create the impression that there is actually no difference between "us and them," celebrities are the same ordinary people, with the same problems as everyone else. Becoming a celebrity is, therefore, a choice available to each of us. This is one of the key factors of the prevalence and intensity of the tendency towards media glory. "The idea that someone can build an identity by depicting someone else has created particular problems in contemporary society. The message that everyone can achieve a life of glamour and fame, if they choose, and make an effort, led countless people to neglect the essential elements of their lives searching for unattainable fantasy" (Salecl, 2014, p.51).

Consumer culture in many respects is referring to technology. Based on that fact consumer culture is also promoting the ability to quickly reject "the old" (goods, values, friends etc.) and even faster to accept "the new ones". According to Teodor Adorn and Max Horkheimer, culture is now subject to exchange, it is fully commodified, it has no longer usable value, and only the exchange value remains (Adorno and Horkhajmer, 1989).

Lifestyles are based on the social organization of consumption. In the contemporary culture of celebrities, dominant values and lifestyles are imposed through the media. We are living in a worldwide community made possible by media and internet, who influences the way we view men, women and family (Rada and Pănescu, 2016). Take, for example, competition for the Miss World, which offers a unique way of life and lifestyle, namely it provides accurate Instructions how people should look, behave, what kind of career they should have. This form of unification undermines the individual's identity and uniqueness.

The Miss World competition manipulates the lifestyle that relates to the exterior. Everything is spectacular, glamorous, but a certain pattern of appearance and behavior is imposed, and distributed through the media mostly to young girls, who then adopt and strive towards such a lifestyle. Today, in the culture of spectacle, instead of increasing the diversity of media content, uniformity is pursued according to the dominant form of sensationalism that gathers the widest audience. The world of spectacle has become a substitute for the grim reality that stuns people by 
keeping them in a state of passivity. The spectacle, which relies on the material-hedonistic value orientation, where conformity, orientation to the outward appearance, leisure life, entertainment and unrealistic desires are the basis of reality, has accomplished the tactics of its domination. It is precisely this form of cultural values that contribute to the development of narcissism (or reinforcing narcissistic predisposition) and pseudo identity in celebrities and people who look up to them and adopt their identity as their own. As for the beauty contests, the ones who look up to contestants are mostly young girls. Sigmund Freud (2011) distinguished primary and secondary narcissism. Primary narcissism is a normal development stage during childhood. Secondary narcissism occurs in adulthood. This narcissism is more of a pathological nature, because it refers to the conditions in which people are self-absorbed, incapable of empathy and interpersonal relationships, and approach people as means of meeting their needs. Narcissism is a love for oneself, for one's own personality. A moderate dose of self-love is necessary for a person to have a positive image of himself/herself. However, excessive self-esteem is considered a psychopathological phenomenon. The characteristic of pathological narcissism is that a person creates a grand self that characterizes omnipotence, expressed perfectionism, a strong motive for achievement, maintaining self-esteem by manipulation, exploitation, and underestimation of others. This self is merely a compensation for a genuine self of a narcissist personality that features a negative image of itself and the abundance of narcissistic injuries from childhood, a sense of emptiness, low self-esteem, a sense of pain, and fragmentation of a false image of oneself, which is built as a defensive mechanism.

Narcissism in the light of game analysis (Cinderella example). Here, as a symbolic illustration, we will show intrapsychic developmental challenges in the process of psychological development of the girl in the light of dynamic psychology and transactional analysis of the popular fairy tale - Cinderella. The analysis was carried out by the authors of the research as an additional qualitative research contribution and support to the interpreted conclusions of this paper.

The beginning of the drama starts with a psychological auto manipulated game "Poor me". Cinderella unquestioningly accepts her difficult fate by believing in her inferiority in relation to other family members. The way others treat her will determine her inner experience of her own value. In order to remain persistent in the role she has accepted, she must isolate all those needs that she acquired by birth - to be important to herself, to know what she feels, to openly seek and take what she needs. Fortunately, growing up and maturing nevertheless spontaneously inflict damage on her wrong decisions and negative adjustment of her personality to the unfavorable living condition. She begins to realize that a different life story, no matter how far from her, is still possible. There are "happy princes" but also "happy princesses" who do not hide in the ashes behind those whom they leave the role of "flamboyant villains" in order to preserve their innocent face and the public presentation of "martyrs". Those same villains do not lack initiative or willpower to live their lives according to their own choices. However, they are really the first to be criticized by the critics who watch the drama from the side. In spite of that, all villains are wholeheartedly accepted in the life of a Cinderella. They help her define and shape her weaknesses, fears, and insecurities, turning them into real virtues compared to the "bad" features of the people she is surrounded by. First of all, in her own eyes, she receives recognition of the identity of a "goody-good" and ceases to believe that she herself is not Ok, although others do not treat her well. I am Ok - others are not Ok, is the motto which she uses to protect herself against deeper injuries. Thanks to that, she has steadily built the identity of a "good girl" in her own eyes, but also in the eyes of the selected audience by the script. Regardless of the fact that those are birds, horses, dogs, and mice, as it is said in fairy tales, it is important that they are from the same story and share her viewpoint. After that, Cinderella is ready for new challenges of social reality. Finally, tired of the game "Poor me", she decides to take risks 
and openly seeks what she wants out of life: fun, opportunity, joy, play, pleasure, and related psychological needs in accordance with the development stage. Of course, she does not get what she seeks right away. Nothing new. "Cannot", "Not now", "Why you," "I won’t," "I can’t," "I don’t know" are just some of the frequent answers when a person needs the cooperation of others to realize his own intentions and ideas. Nevertheless, being free does not mean that the plan would be accomplished in any case. Even the refusal does not mean that "it shouldn't have been asked for". Anyone who is aware of what he really wants and believes he is entitled to it will find a way to get it. Even if it was with the help of the pumpkin, mice, and villas, as it is described in a fairy tale. Of course, leaving a bad life pattern does not mean jumping straight to autonomy. This is simply not the case, not even in fairy tales. So Cinderella withdrew from the game of "victim" for one night to experience how it is to be a "peasant woman". This is a metaphor, and the name of the psychological game designed by Eric Berne, not a derogatory word for a woman who is engaged in agriculture work. "Peasant Woman" has no confidence in herself, uncritically believes people of high status, keeps asking for advice of people who she believes are better and smarter than her, but in the end never listens or applies this advice, she doesn't even remember it, but instead she finds a way to quickly replace them with other eminent advisers or to discredit them as ignorant, even if she doesn't understand or listen to them (Berne, 1996). In the same manner, Cinderella celebrates the importance and significance of the success and value of the people who organize the event and come to such parties. She gives herself the right only to passively observe how others enjoy. And superficially, by her appearance, fits into society, but retains the feeling that she essentially does not belong to the world she admires the most. Today, Instagram would be a lot of help for her to build an image faster and easier to fit in wherever she wants, not even having to be exposed to the challenge of personal confrontation, or conversation.

Subsequently, there is another trap of the new script and dramatic turnaround. The Cinderella has succeeded much more than her original role of the Bystander imposed upon her (Clarkson, 1996). She managed to be noticed and chosen. It was for her capacities and experiences of herself a bit too much at the time, and she avoided a spontaneous and free encounter with the prince, saving herself from the risk of intimacy by the script of Almost. He almost met her and her truth instead of the Instagram picture, but she skillfully managed to escape. There was just one shoe left but it was not enough to know who she really was and to what extent she really was not what she represented.

A persistent prince does not stop here and does not agree to the game. Love pushes him to seek life more than a game. He conducts extensive research, after which, all false arguments and false representations dissipate. Simply, advertising is not sufficient, nor necessary, when we know exactly what we want, and what we do not want. And it is confirmed in the end, regardless of the fact that the sweat, blood, and tears are spilled on the advertisement, just like in the original fairy tale. This is the painful truth of advertisers in today's marketing perspective of all-pervasive digital communications and complete control of users over media and the growing control of consumers over purchasing choices. The one who has the ability to see and to know what he wants is inspiring enough to add to the confidence of those who do not have enough of it as well. There is no ash that could hide quality, nor deception that could mask a bad offer. Cinderella, therefore, reveals her noble person and interest, accepts the risk of intimacy, leaves the game, gives up Cinderella and Instagram beauty as well, and for now, there seems to be no objection.

Narcissism and the public self. After the transaction analysis of Cinderella, a popular narrative that is still developmentally relevant, especially in the psychological development of women, we return to a wider picture. Famous persons have dual aspects of identity - personal and 
public, or private and social. The difference between the individual and social identity can be explained as a distinction between the private and public sphere. The problem is that changes in the content, character and expression of one sphere leave the consequences in the way of expressing another sphere. A celebrity, in order to become one, often has to look and behave in a certain way, which is culturally defined, and media support and broadcast it all for the sake of profit. This uniformity is part of the social identity, that is, the public sphere of celebrities. When this sphere becomes dominant, and when individuality is suppressed, personality problems occur, or pseudoidentity is formed, which in the material-hedonistic value orientation and culture of spectacle is often shown through narcissism and self-absorption. The prescribed rules of public life are not authentic; an individual can achieve self-actualization only through personal experience, personal growth and development. Suffocating freedom in this way, cause or open repressed impulses of hatred and aggression that affect the creation of uniformed and unhappy people, who have suppressed their individualities and the need for personal growth and development, autonomy, firm identity, and integrity. Young people, especially girls, who look up to models, who are also very young themselves, rarely realize that their sense of self-confidence is conditioned by the opinions of others about them, and the behavior of others as well. Their self-respect is conditioned by the success in "managing the image others have about them" and that is the reason why fame is so important to them. It is not only a practical means of acquiring material profit, which may have been a primary motive, but also a means of confirming the importance and value of a person, first of all in their own eyes.

\section{Methodology}

\section{Objectives}

The general goal of this research was to explore in depth motivation and expectations among adolescent girls (from the age 16 to 21) that have chosen to enter a beauty pageant. Competing in sports is normally accompanied by psychological evaluation and preparation for any outcome, winning or losing. This is not the case with beauty competitions, generally speaking, at least not as a part of a standard protocol. We could say that during beauty contest, in particular where high stakes are involved (i.e. national ambassador of beauty), girls are exposed to situations which represent a stressor for them, without undergoing proper preparations or support procedures. In order to better understand the specific needs of a typical contestant, and for the purpose of proposing and developing an adequate response and support network, psychological testing was organized for the finalist, during the last phase of the competition. By that time, they all overcame the initial anxiety and adapted themselves adequately to the role.

\section{Material and methods}

Testing was performed through the application of the projective technique Human figure drawing - Machover test, followed by the semi-structured interview on the meaning presented in the drawing. Various projection drawings have been designed for assessing children's personality and psychological disorders including the tests of drawing a person (DAP). The validity and reliability of the DAP test are satisfactory (Rawley, 2005). This research protocol aimed at assessing the nature and quality of self-perception and self-awareness from the perspective of dominant life goals and values. The projective kind of technique is chosen due to the fact that it bypasses conscious resistance and does not provoke giving of socially preferred response. In addition, candidates were profiled on the basis of the two theoretically similar personality tests, based on the theory of the 
Transactional analysis, one of which was intended to measure dominant defense mechanisms of the personality (test Driver - 35Q), while the other test, Drego Injunction scale (Drego, 1994), was intended to measure a developmental deficit in terms of accurate self and others perception, social skills, and affective fluency and stability. Transactional analysis theorists and researchers consider five such clusters are universally present regardless of gender and national identification (Stewart \& Joines, 1987). In his empirical efforts to develop a scientifically valid driver instrument, Sandström (2015) created a test with the following psychometric characteristics: the values of Cronbach's alpha for the drivers as a measure of reliability for each individual sub-scale are: Hurry Up - 0.83; Be Strong - 0.80; Please Me - 0.82; Try Hard - 0.77; Be Perfect - 0.73. Study of these concepts in Serbia and Croatia gave results that indicate the need for further development of the psychometric characteristics of the Drivers test (Pejić et al., 2015). Drego's scale is a descriptive clinical inventory that is often used by transactional analysis clinicians as a naturalistic method for client assessment, with strong clinical and conceptual validity in quick client description, treatment orientation and understanding based on theory. Empirical validity of Drego's scale is yet to be psychometrically tested and improved by research and clinical application in different cultures, especially outside of the Western world.

As stated above, both tests have been administered previously on the Serbian sample where this research is conducted. Joint administration of these two instruments increased the validity of each of the tests used individually and added to the possibility of a broader understanding of participants' capacity to overcome stress, their dominant interpersonal style and grounding for the sense of self. A total of 20 subjects completed all questionnaires.

Research protocol. Testing was carried out in the presence of psychologists and other subjects, that is, in a group context. The time they needed to complete the tests was 80 minutes, since they were interacting with the examiner so that all the uncertainties related to certain questions and instructions were clarified. This ensured the quality (credibility) of the obtained results and their further usability in the analysis of individual differences, as well as the similarities in the personality profile among the participants.

\section{Results}

The results are given in the form of the narrative summary, containing the crossinterpretation of the results obtained with all three psychometric tools. The reason for the application of combined methodology and narrative analysis of results was to better describe and explain the individual differences between the tested subjects, while, at the same time, narrative analysis provided an insight into some common themes and trends in all the answers given by the participants that came from the same sample group.

In what follows, we will present two illustrative narratives, from a sample of 20 participants, contestants of the Miss World Competition, as a support to the conclusions drawn on the basis of the thematic and interpretive analysis of all the profiles obtained.

Profile of the participant A.Ć. in a narrative form:

High expectations of herself have been taken over by others. The basic motive is to get approval and acceptance from her environment. The participant is not set up independently in her plans. Her success and engagement are conditioned by the circumstances, permissions and encouragement that she seeks of others. Contact with reality is not her strong side; she rather leaves the assessment to others. In trying to respond successfully to others' expectations of herself, she may seem false, 
alienated, rude, distanced or uninterested. As for her authentic expression of personality, the drawing reveals a sense of herself as an "awkward child, stopped in the game".

Profile of the participant T.P. in a narrative form:

Extremely high ambition, as well as expectations from herself. She is strict towards herself, with strong self-criticism. With this profile of personality, responsibility and reliability go together as related characteristics. She does not forget her own failures, nor does she like to be seen and treated as if she were a child (a girl). Self-perception of herself is ahead of her years (she considers herself a "powerful woman", as she states). There is a noticeable conflict within her personality at the level of self-image. On one hand, there is a vision of a powerful woman, and on the other hand, a graphic representation and an accompanying interview show the perception of herself as a playful, carefree and lazy child. It could be assumed that this is exactly the side of her personality she is trying to hide in self-representation. The closeness with others is not valued as a quality, nor is it initiated. She relies more on herself.

Profile of the participant A.Z. in narrative form:

Anxiety and mistrust dominate above other personality traits in this particular psychological profile. In the first place because of other people opinion and acceptance, the interviewee wants to be successful (even perfect, as she claims). It is noticeable that she appreciates the efforts more than the results, which diminishes her ambition on the long run. Self-perception is such that she sees herself as an immature person. From the drawing, we can see that human figure corresponds to the girl's appearance, without any signs that the figure would indicate the self-perception as a girl who is growing into adulthood. The primary criterion in perception and evaluation of oneself is aesthetic in nature. In relations with others, she is presenting her flexibility, poor self-confidence, and unclear personal goals.

Profile of the participant M.N. in a narrative form:

Results point to Introversion in social situations and avoidance of self-analysis and critical review of herself. Primarily, what is important to interviewee is that her performance helps her in seeking of love and acceptance from the people that are close to her. On the other hand, it seems that she does not give herself the right or permission to be open and spontaneous in social situations. Selfconfidence is unstable, "shaky" because it strongly depends on "how others see me." This is not seen in the initial impression based on her appearance by which she is trying to control and hide emotions and strives toward perfectionism. Female figures from her immediate social environment are perceived as the most important role models and support. Striving toward perfection is the dominant defense mechanism reflected in her answers and self-presentation.

Profile of the participant A.S. in a narrative form:

The interviewee has not developed autonomous motivation or her own assessment criteria. She is directed toward others in that sense, which is in accordance with her adolescent phase (being the youngest among the contestants). Analysis of the drawings shows the active interpersonal conflict between two dimensions of the identity (pupil versus professionally engaged individual). In her drawing, she presented herself as an older girl, with a book in one hand and a purse in the other (the symbols of two different tendencies). Motivation is partly irrational ("to be memorable"), especially after comparative analysis of the different results (DAP, Driver and Injunction tests), which point to insecurity and low self-esteem. 
The central theme dominating the majority of answers is the self-image that is not in line with the actual age. Graphical and phenomenological self-report indicates that almost all participants (16 out of 20) perceived themselves as children. That means that self-validation, as well as social context interpretation, is oriented within the regressive frame of reference. In most of the cases, "others" are perceived as threats, while also being granted more power and control compared to the control function attributed to oneself. The results of the interviews show high level for the injunctions - Don't grow up, Don't be you and Don't think. Also, dominant drivers observed are Be perfect, Please others and Try hard. The results clearly support the initial hypothesis that beauty contestants, still in their adolescent and post-adolescent years, need to be carefully selected, motivated and supported in these psychologically provocative situations, such as evaluation and qualification in one-dimensional perspective.

\section{Discussions}

Fame gives the participants of beauty contests (which include Miss World competition) the illusion of being in the center of the world, but, in fact, they are being alienated from the world and themselves as well. The material and hedonistic system of values, the culture of spectacle, the orientation to the exterior, the tendency to fulfill the abundance of desires and desires without delay, media exposure and loss of privacy in order to gain and maintain fame are dominant. All this leads to narcissism or intensifies the already existing narcissistic predisposition in which case identity is connected with the fact to what degree they are accepted by the public and exposed in the media. Here we can speak of the functions of the internalized psychological injunction "Don't Be Important", because people with expressed narcissism as a characteristic (or mechanism of defense in this case) view their sense of identity and values through the prism and opinion of others. For this reason, they are often surrounded by people who would confirm ideas about their "Grand Self". In addition to transactional analysis with interpretation based on concept of Drivers as irrational motivators developed during formative years in reaction to a persistent exposure to social stressors and psychological challenges, we can found theoretical base for associations between sociopsychological deficit, fear of rejection and development of "Grand Self" also in the theory of interpersonal psychoanalysis (Horney, 1937; Sullivan, 1953.). Horney's classification of intrapersonal defense mechanisms, as reactions to an early experience of hostility and threat of rejection, names "self-investment into status and material profit" as one of four different ways to adapt in situations where lack of trust and hope are experienced by a person during developmental years (Chang \& James, 1987).

Money and fame are social, external motives, but there are other, deeper, psychological reasons that lie at the basis of their desire for media exposure. A histrionic personality disorder is closely linked with narcissism. A histrionic personality wants to be always at the center of attention, these individuals often act aggressively and egocentrically and need to feel that "everything revolves around them." They want everyone to love them, to admire and to adore them. They really want recognition. They handle situations in which they do not get what they want with difficulty. These people are too social, often seductive, everything around them is exaggerated, especially emotions. They change their mood often; from the greatest euphoria they fall into the deepest depression. The authors of personal adaptations concept in transactional analysis (Joines and Stewart, 2015) argue that at the basis of this structure of personality lays the fear of rejection that is deeply hidden from self-awareness by intrapersonal dynamics. As children, these people did not get enough love and attention. Here you can recognize a psychological ban, do not be what you are, but be what others expect from you, because this is the only way that this person thinks he can get love and attention. 
Based on the theory of life script analysis, we can say that, in time, these people create beliefs about themselves and others that only if they are liked by everyone, they would be loved. Growing up, their fears have reinforced, as well as the need to impress others. It has become the only way to avoid what they are most terrified of - to be alone and unloved.

The assumption is that one of the main motives that famous people have is the strong psychological need for attention. The need for provoking attention that some famous people have is almost pathological, and their symbiosis with the media is a way to get that attention. Due to the introjected "Don't Be Important" ban, attention is being sought and obtained in an inauthentic way, and thus it is not valued by the person who seeks it pathologically.

Drivers are also important concepts of Transaction Analysis in work with celebrities. Drivers are visible in behavior and represent a certain, predictable behavioral pattern adopted in childhood that has adaptive function for the personality, but inhibits authentic reactions. By conducting Driver Test 35Q, we examined the dominant drivers among the respondents. Driver "Be perfect" can be perceived through focus on appearance and obsession with oneself. The most common attributes of the "Be perfect" driver have to do with performance and appearance; being spotless, clean, with a perfect presentation for others. Narcissistic and histrionic people often manifest this driver, which they project on the outside environment. Striving for perfection or showing the person as perfect is closely linked with the phenomenon of selfie. As for selfie, actor James Franco says: "Selfie is an avatar, a mini version of us, a way to let others know who we are. At a time when the sea of information is available only with a mouse click, the power of attracting the audience is a real power. Selfie attracts attention, and attention is the key word. It is a kind of pseudo-privacy. Selfie is in the era of social networks a way to say - hey this is me" (Džejms, 2014, p.45). The results show that's exactly the same psychological effect the respondents from the sample are trying to reach, only in the traditional way (such as the Miss World competition).

\section{Conclusion}

By analyzing the professional texts (Đurić, 2015) one can conclude that the pseudo identity celebrities build provides a false and ephemeral feeling of security, value, and self-confidence. The psychological need for growth and development and the realization of all the potentials that a person possesses can be suppressed, and the need for love, attention and personal worth can be achieved in an unauthentic manner through symbiosis with the media, success can be equated with fame, but in spite of this, basic needs cannot disappear because they are immanent to human nature.

Numerous studies, as this one, suggest that this kind of pseudo-identity among famous people can cause the appearance of narcissism or reinforce the already existing narcissistic and/or histrionic personality structure, since narcissism has the character of a defensive mechanism. Transactional concepts, such as bans, drivers, psychological games, and life script analysis, aim to uncover the mechanisms of personality dysfunctions in order to provide incentives for the development of authentic forces in person. According to Eric Berne (Berne, 1996), consciousness, spontaneity, and intimacy are basic forces of the autonomous personality.

Advisory and if necessary psychotherapeutic, the strategy for the psychological problems that this research has dealt with, regarding the developmental and psychological vulnerability of young adult women in the light of the popular culture and its negative impacts on personality, implies that in addition to working on the raising the awareness of psychological bans, it is also necessary to perform the analysis of life script, as well as the decontamination of the ego state Adults. The functionality of the ego state Adults is significantly reduced under the influence of life script that is detected as a pattern within the sample, the participants of the study. Then, a therapy 
that follows involves working on a new decision as the antithesis of the script beliefs along with the strengthening of Nursing Parent, who should support a new decision and strengthen the ego state Child by functioning in accordance with the new decisions about a change (Erskin and Morsund, 2015).

As a reminder, all aspects, such as socio-economic, cultural and educational, are inseparable from the individual and vice versa. Personality cannot be developed in isolation, and therefore communication is a basic condition for the development of personalization. Social existence and activity are a necessary precondition for the realization of one's personal life. Therefore, the private and public sphere of personality should not be in dichotomy. Personality achieves its integration when it succeeds in developing its specific abilities and autonomy.

\section{Bibliography}

1. Adorno, T. and Horkhajmer, M., 1989. Dijalektika prosvetiteljstva (Dialectics of Enlightenment), Sarajevo: Veselin Masleša

2. Berne, E., 1996. Games People Play: The Basic Handbook of Transactional analysis. New York: Ballantine Books.

3. Chang, V. and James, M., 1987. Anxiety and projection as related to games and scripts. Transactional Analysis Journal. 17(4), pp.178-184.

4. Clarkson, P., 1996. Bystander games. Transactional Analysis Journal, 23(3), pp.158-172.

5. Erskin, G.R., and Morsund, P.Dž., 2015. Integrativna psihoterapija na delu (Integrative psychotherapy at work), Translation from English by Milan Djurisic, Novi Sad: Psihopolis Institut.

6. Drego, P. 1994. Changing systems through correlations of injunction inventories with analyses of myths and songs. In P. Lapworth, ed. The Maastricht papers: Selections from the 20th EATA Conference, 10-1 July 1994. Amersfoort, Netherlands: Yvonne van Praag. pp. 5-19.

7. Freud, S., 2011. Kompletan uvod u psihoanalizu (A complete introduction to psychoanalysis), Prosveta, Beograd.

8. Graeme, T., 2004. Understanding celebrity. London: Sage.

9. Horney, K. 1937. The neurotic personality of our time. New York: Norton \&Co.

10. Rada, C. and Pănescu, O.M., 2016. Psihologia, psihoterapia familiei şi cuplului. Teorii, cercetări, intervenţii (Psychology, psychotherapy of family and couples. Theories, research, interventions), Bucureşti: Editura Universitară.

11. Pejić. M., Brajović Car, K. and Ellersich, P. 2015. The Psychometric Properties of the Driver test Q 35 in Serbian and Croatian Sample (Poster). University of Zagreb, Faculty of Humanities and Social Sciences, Department of Psychology, 22 ${ }^{\text {nd }}$ International Scientific Meeting in Psychology "Ramirez and Zoran Bujas'days", Zagreb, Croatia.16-18 April 2015.

12. Rawley S. 2005. Aggression and depression assessed through art: Using draw-a-story to identify children and adolescents at risk. New York and Hove: Brunner-Routledge.

13. Rojek, C., 2001. Celebrity, London: Reaktion Books

14. Salecl, R., 2014. Tiranija izbora (The tyranny of choice), Beograd: Arhipelag.

15. Sullivan, H.S., 1953. The interpersonal theory of psychiatry. New York, NY, US: W.W. Norton \& Co.

16. Čejni, D., 2003. Životni stilovi (Lifestyles), Beograd: Clio Publisher.

17. Džons, V., Stjuart, I., 2015. Tipovi ličnosti (Types of personality), Novi Sad: Psihopolis Institut.

18. Đurić, A., 2015. Medijasfera u zagrljaju Velikog brata (Media-embraced Big Brother), Beograd: Čigoja štampa. 
19. Džejms, F., Selfi kaže ovo sam ja (Selfie says this is me). Available at: $\langle$ http://www.politika.rs/rubrike/spektar/digitalnisvet/selfi-kaže-hejovosamja.It.html > [Accessed 22 February 2017].

20. Schmid, D., 2004. Murderabilia: Consuming Fame. M/C Journal, 7(5), Available at: <http://journal.media-culture.org.au/0411/10-schmid.php> [Accessed 14 April 2017].

21. Sandström, S., 2015. Transactional Analysis Driver Test, Available at: $\langle$ http://tadrivertest.com/en/page/13 > [Accessed 10 February 2015]. 